\title{
PROGRAM DINAS SOSIAL DAN TENAGA KERJA KOTA SUBULUSSALAM DALAM MENGATASI PENGEMIS
}

\author{
Fitri Yunita, Salamuddin \\ Program Studi Pengembangan Masyarakat Islam, Fakultas Dakwah dan \\ Komunikasi, Universitas Islam Negeri Sumatera Utara
}

\begin{abstract}
Abstrak: Penelitian ini bertujuan untuk mengungkapkan bagaimana program Dinas Sosial dan Tenaga Kerja Kota Subulussalam dalam mengatasi pengemis, bagaimana realisasi program yang dilakukan oleh Dinas Sosial dan Tenaga Kerja Kota Subulussalam dalam mengatasi pengemis, serta hasil yang telah dicapai oleh Dinas Sosial dan Tenaga Kerja Kota Subulussalam. Penelitian ini menggunakan metode penelitian kualitatif, dengan instrument pengumpul data observasi, wawancara, dan dokumentasi. Hasil dari penelitian, adapun program Dinas Sosial dan Tenaga kerja Kota Subulussalam dalam mengatasi pengemis yaitu pemberdayaan sosial, rehabilitas sosial, jaminan sosial, dan perlindungan sosial. Sedangkan hambatan yang dihadapi oleh Dinas Sosial dan Tenaga Kerja Kota Subulussalam dalam mengatasi pengemis diantaranya tidak adanya penampungam/tempat panti rehabilitas, hal ini menjadi hambatan. Selain hambatan dalam mengatasi pengemis karena belum adanya wadah, atau penampungan/tempat untuk pengemis. Maka dari itu program Dinas Sosial dan Tenaga Kerja dalam mengatasi pengemis sangat penting.
\end{abstract}

Kata kunci: Program, Dinas Sosial, Pengemis

\section{PENDAHULUAN}

Indonesia memiliki sejumlah permasalahan baik masalah sosial atau ekonomi seiring dengan laju pembangunan dan pertumbuhan. Salah satu fenomena sosial saat ini adalah munculnya pengemis, keterlantaran, dan sebagainya. Pengemis ini sering dianggap sebagai sampah masyarakat, karena baik pemerintah maupun masyarakat merasa terganggu oleh kehadiran mereka. Kegiatan pengemis atau meminta-minta dilakukan pada pagi hari sampai sore hari, pengemis melakukan aktivitasnya di tempat keramaian. Pada hakikatnya pengemis adalah seorang yang masih membutuhkan perhatian orang lain terutama dari pemerintah. Contohnya memberikan pendidikan ataupun pelatihan terhadap pengemis.

Pengemis merupakan salah satu golongan masyarakat yang harus mendapatkan perhatian khusus dari pemerintah, terutama tentang kesejahteraan hidup dan kesehatannya. Pengemis adalah sebutan bagi "Penyandang Masalah 
Kesejahteraan Sosial", di antara sebutan lain seperti gelandangan, keterlantaraan, anak jalanan, dan sebagainya, selama ini masalah sosial tersebut tidak kunjung dapat diatasi, paling tidak dikurangi. Pengemis adalah orang-orang yang mendapatkan penghasilan dengan meminta-minta di tempat umum dengan berbagai cara dan alasan untuk mengharapkan belas kasihan dari orang lain. Seharusnya pengemis adalah orang-orang yang benar-benar dalam kesulitan dan mendesak karena tidak ada bantuan dari lingkungan sekitar dan dia tidak punya suatu keahlian yang memadai, bukan karena malas untuk mencari mata pencaharian yang layak.

Pengemis pun saat ini sudah menjadi pekerjaan di setiap umur. Dari mulai anak-anak, hingga mereka yang tua renta menjadi profesi yang sama, yaitu mengemis. Sebenarnya pengemis ini sering kita jumpai didalam kehidupan seharihari baik di persimpangan jalan, ditoko, diwarung dan tempat lainnya. Bahkan fenomena pengemis saat ini menjadi persoalan, pengemis telah banyak menggunakan berbagai modus untuk mendapatkan uluran tangan dari masyarakat sekitarnya. Contohnya mereka menggunakan modus selembar surat dan mengatas namakan Musshalla dan Pasantren untuk kepentingan mereka. Selain faktor ekonomi, kurangnya anggota badan atau cacat fisik, serta tidak memiliki keahlian dalam bekerja dibagian tertentu.

Faktor umur dan kesehatan juga mendorong seseorang untuk menjadi pengemis karena beralasan bahwa tidak ada orang yang akan mempekerjakan orang yang sudah tua dan sakit-sakitan sementara untuk berobat tidak ada biaya jadi salah satu jalannya ialah dengan cara mengemis, untuk menutupi biaya hidup dan untuk berobat. Biasanya seorang pengemis ini masih mempunyai rumah atau tempat tinggal. Bagi para pengemis diatas, nilai-nilai yang mereka anut tentang hal yang "benar" dan "salah" sangatlah berbeda bila dibandingkan dengan anggota masyarakat lainnya. Seperti mereka yang bekerja sebagai karyawan swasta, pegawai negeri, pedagang dan sebagainya. Bagi mereka, meminta menjadi alat utama untuk mendapatkan penghasilan yang ia harapkan.

Terkadang masyarakat tidak suka dengan keberadaan pengemis. Bukan karena calon dermawan tidak ingin berbagai rezeki dengan mereka, tetapi beberapa pengemis ada yang menggunakan hasil meminta-meminta mereka 
dengan hal-hal yang tidak penting. Adapula pengemis yang meminta sedekahnya dengan cara memaksa dan jika si pengemis tidak diberi uang maka si pengemis pun marah-marah sendiri karena kecewa tidak di beri uang.

Pemerintah harus hadir dalam masalah sosial, jika pemerintah abai dalam menangani masalah sosial seperti ini, maka masalah yang ada di masyarakat semakin lama semakin meningkat. Namun begitu, pemerintah belum sepenuhnya bisa menyelesaikan masalah sosial tersebut. Maka dari itu, program Dinas Sosial dan Tenaga Kerja sangat dibutuhkan dalam mengatasi pengemis. Sehingga dengan adanya program Dinas Sosial dan Tenaga Kerjalah dapat mengurangi pengemis. Oleh karena itu Dinas Sosial dan Tenaga kerja selaku bidang kesejahteraan sosial memberikan motivasi atau pelayanan terhadap pengemis yang ada. Hal ini di wujudkan melalui program-program sosial kemasyarakatan, salah satunya program mengatasi pengemis. ${ }^{1}$

Pemerintah akan melakukan langkah-langkah preventif, koersif, dan rehabilitatif demi mensejahterakan kehidupan pengemis dengan memberikan pelatihan khusus agar mempunyai motivasi untuk berjuang hidup, tidak mengandalkan belas kasihan orang lain, namun dengan melakukan sesuatu seperti bekerja. Pemerintah juga memberikan sanksi bagi siapa saja yang masih berbelas kasihan memberikan uang kepada pengemis. Hal ini dilakukan pengemis untuk memberikan efek putus asa bagiu pengemis agar berhenti mengemis dan mengikuti program pelatihan khusus yang di sediakan oleh Pemerintah guna bertahan hidup.

Bagian penyusunan program pemerintah mempunyai tugas pokok melaksanakan sebagian tugas Sekretaris lingkup penyusunan program dan laporan. Contohnya seperti: Penyusunan rencana program dan kegiatan, pengumpulan bahan petunjuk teknis lingkup penyusunan rencana dan program Dinas, penyiapan bahan penyusunan rencana dan program Dinas, penyiapan bahan pembinaan pengawasan dan pengendalian, penyiapan bahan monitoring, evaluasi dan pelaporan Dinas.

${ }^{1}$ Miftachul Huda, Pekerjaan Sosial dan Kesejahteraan Sosial, (Yogyakarta: Pustaka Pelajar, 2009), hlm. 56. 
Di Subulussalam pengemis tidak asing lagi, banyak masyarakat yang mengemis karena tidak ada pekerjaan dan satu-satunya jalan ialah dengan cara mengemis, tujuannya untuk mendapatkan uang. Dalam mencegah permasalahan ini dengan cara menangkap para pengemis yang berkeliaran, dan permasalahan itu tidak akan dibiarkan begitu saja. Mengemis adalah salah satu dari akibat malasnya bekerja, jika dibiarkan begitu saja bisa merusak generasi penerus Kota Subulussalam.

Kota Subulussalam adalah sebuah kota di provinsi Nanggroe Aceh Darussalam. Kota ini dibentuk berdasarkan Undang-undang Nomor 8 Tahun 2007, pada tanggal 2 Januari 2007. Kota ini merupakan pemekaran dari Kabupaten Aceh Singkil. Kota Subulussalam memiliki 5 kecamatan untuk saat ini, yakni Kecamatan Simpang Kiri, Kecamatan Penanggalan, Kecamatan Rundeng, dan Kecamatan Sultan Daulat serta Kecamatan Longkib.

Tugas Dinas Sosial dan Tenaga Kerja ialah suatu lembaga yang ada di Kota Subulussalam yang berperan untuk mengatasi pengemis yang ada di Kota Subulussalam. Dalam hal ini untuk mencapai visi dan misi dari Dinas Sosial dan Tenaga Kerja Kota Subulussalam tersebut terutama tentang pengemis dan lainnya maka lembaga ini melakukan patroli di daerah Kota Subulussalam dalam menugaskan satpol pp untuk razia pengemis yang berkeliaran dijalan.

Permasalahan dalam penelitian ini bahwa penulis ingin mengeta bagaimana program Dinas Sosial dan Tenaga Kerja Kota Subulussalam dal menjalankan programnya sehingga bisa terlaksana dengan baik, dan dampaknya bisa dirasakan oleh masyarakat Kota Subulussalam.

\section{METODOLOGI PENELITIAN}

Jenis penelitian yang digunakan dalam penelitian ini adalah penelitian kualitatif, penelitian kualitatif adalah jenis penelitian yang menghasilkan penemuan-penemuan yang tidak dicapai dengan produser-produser perhitungan. Dengan demikian penelitian ini hanya memaparkan secara deskriptif (gambaran) tentang program Dinas Sosial dan Tenaga Kerja Kota Subulussalam dalam mengatasi pengemis. 
Pendekatan ini adalah deskriptif, yang dimaksud dengan deskriptif adalah laporan ini akan berisi kutipan-kutipan data untuk memberikan gambaran penyajian laporan tersebut. Data tersebut mungkin berasal dari naskah wawancara, catatan lapangan, foto, dan dokumen.

Lokasi penelitian ini adalah di Dinas Sosial dan Tenaga Kerja Kota Subulussalam dan berlokasi di Jalan Lae Oram Komplek Perkantoran BLK, Kota Subulussalam.

Sumber data dalam penelitian ini dapat dibagi kepada dua kelompok, yaitu:

a. Data Primer

yaitu sumber data utama yang diambil atau yang diperoleh dari orangorang yang terlibat langsung dalam penelitian. Dalam penelitian ini, data primer tersebut di dapatkan dari kepala Dinas Sosial dan Tenaga Kerja Kota Subulussalam dalam mengatasi pengemis.

b. Data Sekunder

yaitu data pendukung yang berkaitan dengan penelitian, data ini diperoleh dari buku-buku, peraturan-peraturan yang tertulis atau dokumen yang berkaitan dengan masalah yang diteliti, dan internet yang relevan dengan ${\text { penelitian } \text { ini. }^{2}}^{2}$

Informan penelitian adalah orang yang memberikan informasi tentang situasi dan kondisi latar belakang penelitian. Penetapan informan dalam penelitian ini berdasarkan anggapan bahwa informan dapat memberikan informasi yang diinginkan penelitian sesuai dengan permasalahan penelitian. Informan dalam penelitian ini antara lain :

1. Kepala Dinas Sosial dan Tenaga Kerja Kota Subulussalam Bapak Drs. H. Sanusi, M. Ag.

2. Staff Dinas Sosial dan Tenaga Kerja Kota Subulussalam.

3. Pengemis di Kota Subulussalam

4. Masyarakat Kota Subulussalam

5. Satpol PP Kota Subulussalam

${ }^{2}$ Lexy J Moleong, Metodologi Penelitian Kualitatif, (Bandung: PT Remaja Rosdakarya, 1993), hlm. 105. 
Alasan peneliti menjadikan mereka sebagai informan penelitian adalah mereka selaku yang bekerja didalam Dinas Sosial dan Tenaga Kerja dan mereka mampu memberikan informasi serta mereka juga yang bertanggung jawab atas terlaksananya program-program yang dilaksanakan oleh Dinas Sosial dan tenaga Kerja Kota Subulussalam dalam mengatasi pengemis.

Teknik pengumpulan data yang digunakan dalam penelitian ini adalah:

a. Wawancara

Wawancara yang dimaksud disini ialah wawancara yang dilakukan dalam penelitian secara tatap muka (face to face) dengan maksud tertentu. Percakapan dilakukan oleh dua pihak, yaitu pewancara (interviewer) yang mengajukan pertanyaan dan yang diwawancarai (interviewee) yang memberikan jawaban atas pertanyaan itu. Maksud mengadakan wawancara secara umum adalah untuk menggali struktur kognitif dan dunia makna dari perilaku subjek yang diteliti. ${ }^{3}$

b. Observasi

Observasi merupakan salah satu metode pengumpulan data yang paling alamiah dan paling banyak digunakan tidak hanya dalam dunia keilmuan, tetapi juga dalam berbagai aktivitas kehidupan. Secara umum, observasi berarti pengamatan, penglihatan. Sedangkan secara khusus, dalam dunia penelitian, observasi adalah mengamati dan mendengar dalam rangka memahami, mencari jawab, mencari bukti terhadap fenomena sosial keagamaan (perilaku, kejadian-kejadian, keadaan, benda, dan simbol-simbol tertentu) selama beberapa waktu tanpa mempengaruhi fenomena yang diobservasi, dengan mencatat, merekam, memotret fenomena tersebut guna penemuan data analisis.

c. Dokumentasi

Dokumen ialah teknik pengumpulan dengan menyimpan dokumen yang relevan dan yang terkait dengan permasalahan yang diteliti. ${ }^{4}$

\footnotetext{
${ }^{3}$ Azuar Juliandi \& Irfan, Metodologi Penelitian Kuantitatif, (Bandung: Citapustaka Media Perintis, 2013), hlm. 88.

${ }^{4}$ Imam Suprayogo, Metodolgi Penelitian Sosial, (Bandung: PT Remaja Rosdakarya offset, 2003), hlm. 167.
} 
Teknik yang dilakukan peneliti dalam menganalisis data yang sudah diperoleh menggunakan wawancara, observasi, serta dokumen-dokumen yang diperoleh saat melakukan penelitian. Untuk melihat hasil sesuai dengan kriteria yang dicapai, maka peneliti menggunakan reduksi data. Reduksi data ialah kegiatan yang mengaktiarkan hasil pngumpulan data selengkap mungkin dan memilah-milah dalam satuan konsep tertentu. Maka peneliti akan melihat data tersebut sehingga mendapatkan hasil yang sesuai dengan tujuan.

Setelah data yang dibutuhkan terkumpul, maka selanjutnya peneliti melakukan analisis mengenai data-data tersebut. Untuk proses penganalisaan data, maka penganalisaan dilakukan dengan analisa domain (domain analysis). Maksudnya ialah peneliti hanya menargetkan untuk memperoleh gambaran seutuhnya dari objek yang diteliti tanpa harus merinci secara detail unsur-unsur yang ada didalam keutuhan objek yang diteliti. ${ }^{5}$

Untuk itu data yang didapat dianalisis dengan menggunakan analisis data kualitatif model interaktif yang terdiri dari:

1. Reduksi Data yaitu menggolongkan atau menkode data atau sebagai proses pemilihan, pemusatan, perhatian, pada penyederhanaan, pengabstrakan, dan transformasi data yang muncul dari catatan yang tertulis dilapangan.

2. Penyajian Data

Ialah sekumpulan informasi tersusun yang memberi kemungkinan adanya penarikan kesimpulan dan pengambilan tindakan.

3. Menarik Kesimpulan/verifikasi

Setelah data disajikan yang juga dalam rangkaian analisis data maka proses selanjutnya adalah penarikan kesimpulan atau verifikasi data. Proses verifikasi data dalam hal ini adalah tinjauan ulang terhadap catatan lapangan. Data yang telah diperoleh dari catatan-catatan lapangan, dari informasi dan informan yang telah ditemukan, diuji kembali dengan menanyakan kembali pertanyaan yang sama diakhir

\footnotetext{
hlm.55

${ }^{5}$ Bagong Syanto, Metode Penelitian Sosial, (Jakarta: Kharisma Putra Utama, 2005),
} 
penelitian ini dan melakukan wawancara kepada Kepala Dina Sosial, staff dan masyarakat sekitar.

4. Triangulasi

Triangulasi yang digunakan dalam penelitian ini adalah triangulasi sumber. Triangulasi sumber berarti membandingkan dan mengecek balik derajat kepercayaan suatu informasi yang diperoleh melalui waktu dan alat pertanyaan yang berbeda. Hal itu dicapai dengan jalan:

1) Membandingkan data hasil pengamatan dengan data hasil wawancara;

2) Membandingkan apa dikatakan orang di depan umum dan apa yang dikatakan orang secara pribadi;

3) Membandingkan apa yang dikatakan orang-orang tentang situasi penelitian dengan apa yang dikatakannya sepanjang waktu;

4) Membandingkan hasil wawancara dengan isi suatu dokumen yang berkaitan. ${ }^{6}$

\section{HASIL PENELITIAN}

\section{Program Dinas Sosial dan Tenaga Kerja Kota Subulussalam}

Berdasarkan wawancara yang dilakukan peneliti dengan Bapak Muhammad Fauzi SE, selaku bidang program dan pelaporan pada hari Kamis tanggal 05 April 2018 jam 13.30. Beliau mengatakan program dan pelaksanaan yang dilakukan oleh Dinas Sosial dan Tenaga Kerja diantaranya yaitu:

1) Pemberdayaan Sosial

Pemberdayaan Sosial Menurut pasal 1 ayat (10) Undang-undang Nomor 11 tahun 2009 tentang Kesejahteraan Sosial berbunyi semua upaya yang diarahkan untuk menjadikan warga negara yang mengalami masalah sosial mempunyai daya, sehingga mampu memenuhi kebutuhan dasarnya. Pada intinya, pemberdayaan sosial ini berorientasi bagaimana cara memberdayakan seseorang, keluarga, kelompok dan masyarakat seperti pengemis yang mengalami masalah kesejahteraan sosial agar mereka mampu memenuhi kebutuhan hidup secara mandiri.

\footnotetext{
${ }^{6}$ Ibid, hlm. 187.
} 
2) Rehabilitas Sosial

Upaya rehabilitasi sosial sebagaimana dijelaskan didalam pasal 7 yang melalui:

a. Motivasi dan diagnosa psikososial

b. Bimbingan mental spritual

c. Bimbingan fisik

d. pelayanan aksesibilitasi

e. Bantuan dan asistensi sosial

f. Bimbingan resosialisasi

3) Jaminan Sosial

Jaminan sosial ini sering kali digunakan sebagai alternatif istilah perlindungan sosial.

4) Perlindungan Sosial

Perlindungan sosial merupakan keseluruhan dari kegiatan pembangunan dibidang sosial. Perlindungan sosial berdasarkan pelaksanaan pelayanan, yakni pemerintah.

\section{Kegiatan Dinas Sosial dan Tenaga Kerja Kota Subulussalam}

1) Pelestarian Kepahlawanan, Keperintisan dan Kesetiakwanan Sosial

2) Penanggulangan Kemiskinan

3) Pemberdayaan Keluarga dan Kelembagaan Kesejahteraan Sosial

4) Rehabilitas Sosial Orang dengan Kecacatan (ODK)

5) Rehabilitasi Tuna Sosial

6) Rehabilitasi dan Perlindungan Sosial

7) Rehabilitasi Lanjut Usia

8) Perlindungan Sosial Bencana Alam dan Bencana Sosial

9) Perlindungan Sosial Korban Tindak Kekerasan dan Pekerja Migran

10) Jaminan Kesejahteraan Sosial (PKH)

11) Pengumpulan dan Pengelolaan Sumber Dana Sosial

12) Bantuan Sosial Korban Bencana Alam dan Sosial

13) Penyelenggaraan Hari Besar Nasional dan Keagamaan

14) Pembinaan Organisasi Perempuan 
15) Monitoring eveluasi dan Pelaporan ${ }^{7}$

Tabel 1. Data Populasi Penyandang Masalah Kesejahteraan Sosial

\begin{tabular}{|c|c|c|c|}
\hline No. & Jenis Permasalahan Kesejahteraan Sosial & Jumlal & \\
\hline 1. & Pengemis, Gelandangan dan Pemulung & 460 & Jiwa \\
\hline 2. & $\begin{array}{l}\text { Anak Terlantar (termasuk anak yatim, piatu dan } \\
\text { yatim piatu) }\end{array}$ & 1.725 & Jiwa \\
\hline 3. & Anak yang memerlukan perlindungan khusus & 3 & Jiwa \\
\hline 4. & Anak Jalanan & 2 & Jiwa \\
\hline 5. & Lanjut Usia & 1.347 & Jiwa \\
\hline 6. & Jut Usia Terlantar & 277 & Jiwa \\
\hline 7. & Anak Disabilitas & 59 & Jiwa \\
\hline 8. & Penyandang Disabilitas & 564 & Jiwa \\
\hline 9. & Perempuan Rawan Sosial Ekonomi & 1.202 & KK \\
\hline 10. & Fakir Miskin & 3.185 & KK \\
\hline 11. & $\begin{array}{l}\text { Keluarga Rentan/Keluarga Bermasalah Sosial } \\
\text { Psiko }\end{array}$ & 208 & KK \\
\hline 12. & $\begin{array}{l}\text { Bekas Warga Binaan Lembaga Pemasyarakatan } \\
\text { (Eks Narapidana) }\end{array}$ & 25 & Jiwa \\
\hline 13. & Korban Bencana Alam & 1.442 & Jiwa \\
\hline 14. & Korban Bencana Sosial & 9 & Jiwa \\
\hline 15. & Keluarga Berumah Tidak Layak Huni & 2.050 & KK \\
\hline 16. & Komunitas Adat Terpencil (KAT) & 125 & KK \\
\hline 17. & Anak yang berhadapan dengan hukum & 1 & Jiwa \\
\hline \multicolumn{3}{|c|}{ Jumlah: 12.684} & \\
\hline
\end{tabular}

${ }^{7}$ Hasil Wawancara dengan Bapak Muhammad Fauzi SE, selaku Bidang Program dan Pelaporan Pada Hari Kamis 05 April 2018 Jam 13.30. 
Dari tabel di atas, menunjukkan bahwa bukan semua orang Subulussalam itu pengemis, tetapi kebanyakan pendatang yang datang ke Kota Subulussalam dengan tujuan mengemis. Dari Observasi yang peneliti lakukan ke lapangan bahwa masih ada pengemis yang terlihat sehat atau masih sanggup untuk bekerja, namun berbagai modus mereka lakukan untuk mendapatkan uang dari masyarakat Kota Subulussalam. Bagi mereka, meminta-minta adalah alat utama mereka untuk mendapatkan penghasilan yang ia harapkan.

Selanjutnya peneliti juga mewancarai Ibuk Laini seorang pengemis yang ada di Kota Subulussalam pada hari Senin tanggal 09 April 2018 jam 09.00. Beliau mengatakan bahwa dia bukan berasal dari Kota Subulussalam, tetapi ibuk tersebut sebagai orang pendatang. Tujuannya untuk meminta-minta uang kepada masyarakat Kota Subulussalam, alasannya karena tidak adanya pekerjaan dan satu-satunya jalan ialah dengan cara mengemis untuk memenuhi kebutuhan sehari-hari. $^{8}$

Adapun penghasilan /hari yang di dapat oleh pengemis yang di kemukan oleh Ibuk Ratna Sebagai pengemis yaitu sebagai berikut:

\begin{tabular}{|l|l|l|}
\hline No & Penghasilan/hari & Penghasilan/bulan \\
\hline 1 & Rp 30.000 & Rp 900.000 \\
\hline 2 & Rp 50.000 & Rp 1.500 .000 \\
\hline 3 & Rp 70.000 & Rp 2.100 .000 \\
\hline 4 & Rp 100.000 & $\operatorname{Rp~} 3.000 .000$ \\
\hline \multicolumn{2}{|r|}{ Sumber Data 2017 } \\
\hline
\end{tabular}

Tabel di atas memperlihatkan pengemis di Kota Subulussalam yakni penghasilan setiap harinya mulai dari Rp 30.000 sampai dengan Rp 100.000. Dengan demikian penghasilan pengemis setiap bulannya mulai dari Rp 900.000 hingga sampai dengan Rp 3.000.000. Sejumlah pengemis mengakui, aktivitas pengemis merupakan pilihan terakhir karena tidak bisa mendapatkan pekerjaan yang layak untuk memenuhi kebutuhan kehidupan sehingga para pengemis tetap bertahan di jalanan.

\footnotetext{
${ }^{8}$ Hasil Wawancara dengan Ibu Laini seorang Pengemis di Kota Subulussalam, Senin 09 April 2018 Jam 09.00.
} 
Berdasarkan wawancara yang peneliti lakukan dengan Ibuk Tami yang berasal dari Longkip sebagai pengemis Kota Subulussalam. Beliau mengatakan bahwa "saya seorang yang miskin yang tidak punya apa-apamau makan juga susah, keadaan juga kurang sehat, makanya saya mengemis, saya mengemis biasa di tempat-tempat yang ramai, seperti di lampu merah dan di temapat SPBU, yang pendapatan saya yang tidak seberapa, kadang saya dapat 100.000 sehari, itu saja tidak cukup untuk kebutuhan sehari-hari untuk 5 orang dan anak-anak saya juga sakit dirumah".

Peneliti juga mewancarai Ibuk Tina yang berasal dari luar Kota Subulussalam. Beliau mengatakan bahwa " saya sebenarnya malu sama keluarga di kampung, karena pernah ada tetangga dari kampung liat saya tengah mengemis di jalan, makanya saya tidak mau pulang kekampung, selain saya malu dikampung juga susah untuk cari kerja, makanya saya mengemis ke Subulussalam, saya mengemis di Subulussalam sekitar 5 tahun, demi melanjutkan hidup, menurut saya caranya seperti ini yaitu mengemis, kalau masalah pendapatan kadang 30.000 sampai 40.000 perhari yang cukupnya untuk makan”.

Dari hasil wawancara dapat disimpulkan bahwa faktor-faktor penyebab menjadi pengemis itu sebagai berikut.

\section{a. Masalah Kemiskinan}

Kemiskinan dapat memaksa seseorang menjadikan pengemis karena faktor ekonomilah yang mendorong untuk seseorang itu menjadi seorang pengemis di jalan.

b. Masalah pendidikan

Pada umumnya tingkat pendidikan pengemis itu rendah sehingga menjadi suatu kendala bagi mereka untuk memperoleh pekerjaan yang layang untuk mereka.

\section{c. Masalah Keterampilan Kerja}

Pada umumnya seorang pengemis itu tidak memiliki keterampilan dalam pekerjaan atau tidak mempunyai keahlian dalam bidang pekerjaan. Karena keterampilan itu merupakan salah satu modal dalam kehidupan. Oleh karena itu, kegiatan pengemis adalah pilihan yang paling gampang untuk dilaksanakan guna memperoleh penghasilan secara mudah. 
d. Masalah Sosial Budaya

Kondisi sosial budaya terjadi karena dipikiran para pengemis muncul kecendrungan bahwa pekerjaan yang dilakukan tersebut adalah sesuatu yang biasa-biasa, selayaknya pekerjaan lain yang bertujuan untuk memperoleh penghasilan. Sehingga membudaya oleh para pengemis untuk memperoleh penghasilan di tempat umum.

Ada beberapa faktor sosial budaya yang mengakibatkan seseorang menjadi pengemis, yaitu:

a. Rendahnya harga diri pada sekelompok orang, mengakibatkan tidak dimilikinya rasa malu untuk meminta-minta.

b. Sikap pasrah pada nasib, menganggap bahwa kemiskinan dan kondisi mereka sebagai pengemis adalah nasib, sehingga tidak ada kemauan untuk melakukan perubahan.

c. Kebebasan dan kesenangan hidup mengelandang, ada kenikmatan tersendiri bagi sebagian besar pengemis, karena mereka merasa tidak terikat oleh aturan atau norma yang kadang-kadang membenahi mereka, sehingga mengemis menjadi salah satu mata pencaharian.

Uraian di atas menunjukkan bahwa benar adanya beberapa faktor sosial budaya yang menjadi penyebab munculnya pengemis dalam kehidupan masyarakat.

Tabel 2. Penetapan Penerimaan Bantuan Asistensi Sosial Bagi Orang dengan Kecacatan (ODK) / Pengemis Kota Subulussalam Tahun 2017

\begin{tabular}{|l|l|l|l|l|l|l|}
\hline No & Nama & Umur & $\begin{array}{l}\text { Jenis } \\
\text { Kelamin }\end{array}$ & Desa & Kecamatan & Ket \\
\hline 1. & Firda & 11 & $\operatorname{Pr}$ & Sikalondang & Simpang Kiri & \\
\hline 2. & Rio & 4 & Lk & Pegayo & Simpang Kiri & \\
\hline 3. & Kasir & 12 & Lk & $\begin{array}{l}\text { Subulussalam } \\
\text { Utara }\end{array}$ & Simpang Kiri & \\
\hline 4. & Putri & 19 & Pr & $\begin{array}{l}\text { Subulussalam } \\
\text { Utara }\end{array}$ & Simpang Kiri & \\
\hline 5. & Asrin & 29 & Lk & Sikalondang & Simpang Kiri & \\
\hline 6. & Rahayu & 42 & Pr & Mukti Makmur & Simpang Kiri & \\
\hline 7. & Rahmad & 30 & Lk & Belegen Mulia & Simpang Kiri & \\
\hline 8. & Sarina & 23 & Pr & Belegen Mulia & Simpang Kiri & \\
\hline
\end{tabular}




\begin{tabular}{|c|c|c|c|c|c|}
\hline 9. & Annisa & 57 & $\operatorname{Pr}$ & $\begin{array}{l}\text { Subulussalam } \\
\text { Selatan }\end{array}$ & Simpang Kiri \\
\hline 10. & Musrifin & 9 & Lk & Lae Oram & Simpang Kiri \\
\hline 11. & Alfian & 3 & Lk & $\begin{array}{l}\text { Subulussalam } \\
\text { Utara }\end{array}$ & Simpang Kiri \\
\hline 12. & Lida & 36 & Lk & $\begin{array}{l}\text { Subulussalam } \\
\text { Utara }\end{array}$ & Simpang Kiri \\
\hline 13. & Musliman & 35 & Lk & $\begin{array}{l}\text { Subulussalam } \\
\text { Barat }\end{array}$ & Simpang Kiri \\
\hline 14. & Suti & 24 & Lk & $\begin{array}{l}\text { Subulussalam } \\
\text { Barat }\end{array}$ & Simpang Kiri \\
\hline 15. & Aman & 34 & Lk & $\begin{array}{l}\text { Subulussalam } \\
\text { Utara }\end{array}$ & Simpang Kiri \\
\hline 16. & Parisah & 46 & $\operatorname{Pr}$ & Tangga Besi & Simpang Kiri \\
\hline 17. & Jamal & 54 & Lk & Subulussalam & Simpang Kiri \\
\hline 18. & Esmi & 49 & Pr & Subulussalam & Simpang Kiri \\
\hline 19. & Angelina & 6 & $\operatorname{Pr}$ & Pegayo & Simpang Kiri \\
\hline 20. & Kajal & 62 & Lk & $\begin{array}{l}\text { Subulussalam } \\
\text { Selatan }\end{array}$ & Simpang Kiri \\
\hline 21. & Edi & 22 & Lk & Mukti Makmur & Rundeng \\
\hline 22. & Permandi & 13 & Lk & Badar & Rundeng \\
\hline 23. & Laini & 47 & $\operatorname{Pr}$ & Badar & Rundeng \\
\hline 24. & Afniyanti & 5 & $\operatorname{Pr}$ & Sibuasan & Rundeng \\
\hline 25. & Mahdi & 23 & Lk & Harapan Baru & Rundeng \\
\hline 26. & Elpina & 13 & $\operatorname{Pr}$ & Blukur Makmur & Rundeng \\
\hline 27. & Mazril & 5 & Lk & Lae Pemualan & Rundeng \\
\hline 28. & Banjir & 57 & Lk & Dah & Rundeng \\
\hline 29. & Perengis & 37 & $\operatorname{Pr}$ & Dah & Rundeng \\
\hline 30. & Yuzi & 12 & Lk & Badar & Rundeng \\
\hline 31. & Purqan & 2 & Lk & Sibungke & Rundeng \\
\hline 32. & Sarjono & 36 & Lk & Binanga & Rundeng \\
\hline 33. & Abdul & 14 & Lk & Lae Saga & Longkip \\
\hline 34. & Supialim & 14 & Lk & Darussalam & Longkip \\
\hline 35. & Siti & 20 & $\operatorname{Pr}$ & Darul Aman & Longkip \\
\hline 36. & Maya & 22 & $\operatorname{Pr}$ & Sikerabang & Longkip \\
\hline 37. & Zeki & 11 & Lk & Longkip & Longkip \\
\hline 38. & Aprilia & 13 & PR & Meranti & Longkip \\
\hline 39. & Anas & 4 & Lk & Lae Saga & Longkip \\
\hline
\end{tabular}




\begin{tabular}{|c|c|c|c|c|c|}
\hline 40. & Raskin & 20 & $\mathrm{Lk}$ & Dasan Raja & Penanggalan \\
\hline 41. & Sanusi & 15 & $\mathrm{Lk}$ & $\begin{array}{l}\text { Penanggalan } \\
\text { Barat }\end{array}$ & Penanggalan \\
\hline 42. & Mukis & 43 & Lk & Lae Bersih & Penanggalan \\
\hline 43. & Buyung & 23 & $\mathrm{Lk}$ & Lae Bersih & Penanggalan \\
\hline 44. & Reza & 16 & $\mathrm{Lk}$ & $\begin{array}{l}\text { Penanggalan } \\
\text { Barat }\end{array}$ & Penanggalan \\
\hline 45. & Mutiara & 61 & $\operatorname{Pr}$ & Penanggalan & Penanggalan \\
\hline 46. & Ali & 69 & $\mathrm{Lk}$ & Penanggalan & Penanggalan \\
\hline 47. & Zainudin & 55 & $\mathrm{Lk}$ & $\begin{array}{l}\text { Penanggalan } \\
\text { Timur }\end{array}$ & Penanggalan \\
\hline 48. & Anugerah & 8 & $\mathrm{Lk}$ & Dasan Raja & Penanggalan \\
\hline 49. & Kuyuh & 61 & $\mathrm{Lk}$ & Penanggalan & Penanggalan \\
\hline 50. & Rudi & 48 & $\mathrm{Lk}$ & $\begin{array}{l}\text { Penanggalan } \\
\text { Barat }\end{array}$ & Penanggalan \\
\hline 51. & Julianti & 30 & $\operatorname{Pr}$ & Jontor & Penanggalan \\
\hline 52. & Jilek & 20 & $\mathrm{Lk}$ & Kuta Tengah & Penanggalan \\
\hline 53. & Rison & 21 & $\mathrm{Lk}$ & Sikelang & Penanggalan \\
\hline 54. & Putri & 28 & $\operatorname{Pr}$ & Penuntungan & Penanggalan \\
\hline 55. & Kamaru & 57 & $\mathrm{Lk}$ & Namo Buaya & Sultan Daulat \\
\hline 56. & Rasmito & 58 & $\mathrm{Lk}$ & $\begin{array}{l}\text { Cipare-pare } \\
\text { Timur }\end{array}$ & Sultan Daulat \\
\hline 57. & Aris pani & 38 & $\mathrm{Lk}$ & Namo Buaya & Sultan Daulat \\
\hline 58. & Tana & 28 & $\mathrm{Lk}$ & Namo Buaya & Sultan Daulat \\
\hline 59. & Ahmad & 12 & $\mathrm{Lk}$ & Bunga Tanjung & Sultan Daulat \\
\hline 60. & Rama & 21 & $\operatorname{Pr}$ & Sigrun & Sultan Daulat \\
\hline 61. & Anhar & 7 & $\mathrm{Lk}$ & Bawan & Sultan Daulat \\
\hline 62. & Linda & 12 & $\operatorname{Pr}$ & Jabi-jabi & Sultan Daulat \\
\hline 63. & Yasikli & 13 & $\mathrm{Lk}$ & Gunung Bakti & Sultan Daulat \\
\hline 64. & Idrus & 52 & $\mathrm{Lk}$ & Lae Langge & Sultan Daulat \\
\hline 65. & Teguh & 1 & $\mathrm{Lk}$ & Batu Napal & Sultan Daulat \\
\hline 66. & Bidur & 53 & $\operatorname{Pr}$ & Gunung Bakti & Sultan Daulat \\
\hline 67. & Fatimah & 48 & $\operatorname{Pr}$ & Gunung Bakti & Sultan Daulat \\
\hline 68. & Roslina & 33 & $\operatorname{Pr}$ & Gunung Bakti & Sultan Daulat \\
\hline
\end{tabular}

Sumber : Laporan Rekapitulasi Jumlah Penerimaan Bantuan Asistensi Sosial. 


\section{Realisasi yang dilakukan Dinas Sosial dan Tenaga Kerja Kota Subulussalam dalam Mengatasi Pengemis}

Realisasi berupa pengintegrasian konsep yang berorientasi secara eksternal, dan bagaimana upaya yang dilakukan agar dapat menjadi dasar bagi pencapaian tujuan dan sasaran lembaga/organisasi.

Hasil dari wawancara yang peneliti lakukan dengan Bapak Adnan, S.Ag, selaku Kepala Sub Bagian Umum dan Kepegawaian pada hari Rabu tanggal 11 April 2018 jam 10.25. Beliau mengatakan ada beberapa realisasi yang dibuat oleh Dinas Sosial dan Tenaga Kerja Kota Subulussalam dalam mengatasi pengemis, yaitu:

1. Sosialisasi Dinas Sosial dan Tenaga Kerja Kota Subulussalam ke masyarakat

Melihat banyaknya masalah yang dihadapi oleh masyarakat, khususnya masalah sosial. Hal ini bukan saja terjadi kepada orang dewasa, atau orang tua tapi juga sampai kepada anak-anak. Maka Pelaksanaan sosialisasi Dinas Sosial dan Tenaga Kerja ke masyarakat merupakan hal yang sangat penting dilakukan, karena dengan melakukan sosialisasi dengan masyarakat dapat menurunkan angka pengemis atau meminta-minta yang ada di Kota Subulussalam.

2. Pembinaan Kesadaran Islam

Dalam melakukan pembinaan kesadaran islam kepada masyarakat yang mengemis atau meminta-minta memerlukan waktu yang tidak sebentar, karena masih banyaknya masyarakat yang mengemis dan masyarakat yang lain sebagian terganggu dengan datangnya seorang pengemis. Alasannya karena sebagian pengemis itu meminta itu dengan cara yang memaksa.

Untuk lebih terwujudnya kesadaran Islam bagi masyarakat yang memintaminta, maka Dinas Sosial dan Tenaga Kerja Kota Subulussalam mempunyai program, yaitu Pemberdayaan Sosial, Rehabilitasi Sosial, Jaminan Sosial, dan memberikan Perlindungan Sosial. ${ }^{9}$

Selain itu, realisasi yang dilakukan Dinas Sosial dan Tenaga Kerja Kota Subulussalam dalam mengatasi pengemis yaitu:

\footnotetext{
${ }^{9}$ Hasil Wawancara dengan Bapak Adnan S.Ag selaku Kepala Sub Bagian Umum dan Kepegawaian Kamis 03 Mei 2018 Jam 09.30.
} 
a. Meningkat kualitas program pelayanan rehabilitasi, pemberdayaan dan perlindungan sosial bagi peningkatan derajat kesejahteraan Penyandang Masalah Kesejahteraan Sosial (PMKS).

b. Mengembangkan mutu dan kapabilitas Sumber Daya Manusia (SDM) penyelenggara kesejahteraan sosial serta mengoptimalkan fungsi sarana dan prasarana pelayanan kesejahteraan sosial.

c. Menjadikan semua program dan kegiatan pelayanan kesejahteraan sosial sebagai tanggung jawab bersama antara pemerintah dan masyarakat.

d. Mendorong dan mengembangkan penyelenggaraan kesejahteraan sosial berbasis masyarakat melalui penyuluhan sosial untuk mengembangkan keswadayaan sosial masyarakat guna mencegah dan menanggulangi permasalahan kesejahteraan sosial di lingkungan masing-masing.

e. Menggali dan memberdayakan potensi dan Sumber Kesejahteraan Sosial (PSKS), serta memperluas dan memperkuat jaringan kerja dalam penyelenggaraan kesejahteraan sosial.

f. Menggali, mengembangkan dan memupuk peningkatan modal sosial dalam penyelenggaraan kesejahteraan sosial.

\section{Hambatan Dinas Sosial dan Tenaga Kerja Kota Subulussalam dalam Mengatasi Pengemis}

Adapun Kendala yang dihadapi dalam mengatasi pengemis ini karena tidak adanya penampugan/tempat panti rehabilitas, hal ini menjadi hambatan. Mengapa saat ini penanganan yang dilakukan belum sepenuhnya efektif, selain hambatan dalam penanganan pengemis karena belum adanya wadah, atau penumpangan/tempat untuk pengemis. Program Dinas Sosial dan Tenaga Kerja dalam mengatasi pengemis ini sangat penting. Untuk menuntaskan Penyandang Masalah Kesejahteraan Sosial (PMKS) di Kota Subulussalam.

Kemudian peneliti melakukan wawancara dengan salah satu karyawan yang ada di Kantor Dinas Sosial dan Tenaga kerja Kota Subulussalam yang benama Ade Maulida MA. Beliau mengatakan bahwa Ada beberapa hambatan atau kendala yaitu belum tersedianya panti rehabilitas untuk membina atau 
menangani pengemis. Adapun hambatan-hambatan di antara lain adalah sebagai berikut:

1. Hambatan dalam mengatasi pengemis ini yaitu belum tersedianya panti rehabilitas sosial seperti penumpangan untuk pengemis yang tertangkap, percuma saja karena pengemis yang tertangkap hanya dilakukan pendataan setelah itu dibebaskan, kemudian mereka mengulangi perbuatannya karena terdesaak oleh kebutuhan sehari-hari.

2. Pekerjaan patroli yang dilakukan oleh Dinas Sosial dan Tenaga Kerja sering mendapatkan perlawanan, seperti mereka memberontak dan berusaha melarikan diri agar tidak tertangkap oleh petugas yang melakukan penertiban.

3. Pengemis yang ada di Kota Subulussalam termasuk kategori anak-anak dan pengemis lanjut usia, sehingga pada saat melakukan pembinaan sulit memberikan penghargaan seperti pengemis lainnya.

Berdasarkan kategori-kategori pengemis dapat di lihat pada tabel di bawah ini:

Tabel 3. Jumlah Pengemis Berdasarkan Usia

\begin{tabular}{|c|l|c|}
\hline No & Kategori Pengemis & Jumlah \\
\hline 1 & Anak-anak & 26 \\
\hline 2 & Lanjut Usia & 48 \\
\hline & Jumlah & 74 \\
\hline
\end{tabular}

Sumber: Data kategori pengemis 2017

Berdasarkan dari wawancara yang peneliti lakukan dengan Bapak Musrifin sebagai karyawan di Dinas Sosial dan Tenaga Kerja Kota Subulussalam. Beliau mengatakan bahwa jumlah pengemis yang ada di Kota Subulussalam tahun 2017 sampai 2018 masing-masing berjumlah 59 orang dan 32 orang artinya jumlah pengemis tahun 2018 ini menurun dibanding tahun 2017.

Jumlah pengemis yang berada di Kota Subulussalam, salah satu faktor disebabkan seseorang menjadi pengemis yaitu, karena faktor ekonomi/faktor kemiskinan, kecacatan fisik, dan ada yang pengemis yang berasal dari luar Kota Subulussalam. Kegiatan ini merupakan runitinas sehari-hari dan telah menjadi mata pencaharian yang utama. Berdasarkan hasil penulusuran identitas pengemis pada saat terjaring Dinas Sosial dan Tenaga Kerja Kota Subulussalam. 
Hal ini seperti yang di ungkapkan oleh Jamal (54 tahun) merupakan seorang pengemis yang berasal Subulussalam Kecamatan Simpang Kiri. Berdasarkan hasil wawancara sebagai berikut:

"Saya asalnya dari Subulussalam Kecamatan Simpang Kiri, saya mengemis sekitar 12 tahun, dulu saya pindah-pindah tempat mengemis, sekarang saya mengemis di tempat keramaian contohnya di pajak Subulussalam, mulai mengemis mulai dari jam 09.00-12.30. Penghasilan yang di dapat sekita 30.000 perhari”.

Hasil wawancara di atas peneliti dapat menyimpulkan bahwa pengemis di Kota Subulussalam ada yang berasal dari Subulussalam sendiri dan ada yang berasal dari luar Kota Subulussalam. Contohnya yang luar dari Kota Subulussalam itu seperi Aceh Singkil, Aceh Selatan, dan sebagainya.

Selanjutnya berdasarkan hasil wawancara yang peneliti lakukan dengan salah satu masyarakat Kota Subulussalam tentang pengemis, atas nama Ibu Rani yang bekerja sebagai Ibu rumah tangga yang tinggal di sekitar Kota Subulussalam tepatnya di Lae Bersih Kecamatan Penanggalan. Beliau mengatakan dengan kehadiran pengemis di Kota Subulussalam saya merasa resah dengan adanya pengemis atau yang meminta-minta yang menganggu kenyamanan masyarakat. Ibu Rani pun mengatakan berharap kepada pemerintah agar pemerintah menciptakan lapangan pekerjaan baru supaya pengangguran berkurang yang akhirnya kesejahteraan masyarakat akan lebih baik untuk kedepannya.

Kemudian hasil wawancara yang peneliti lakukan dengan Ibu Sumiati yang berasal dari Subulussalam. Adapun tanggapan Ibu Sumiati tentang pengemis yang ada di Kota Subulussalam. Ibu Sumiati mengatakan bahwa sebenarnya saya risih melihat banyaknya pengemis, karena saya berpikir apa tidak ada pekerjaan lain selain mengemis, terkadang para pengemis berpura-pura kalau keadaan mereka cacat, sehingga membuat orang yang melihat iba. Terkadang para pengemispun membawa anaknya untuk ikut mengemis juga, sebenarnya saya juga sedih ketika melihat seorang anak yang dijadikan seorang pengemis. Ibu Sumiati juga mengatakan setidaknya pemerintah membuat rumah untuk para pengemis, sehingga mereka tidak perlu tidur di jalanan. Anak di bawah umur pun jadi harus bekerja karena orang tuanya yang tidak sanggup membiayai sekolah anaknya. 
Seharusnya pemerintah lebih memperhatikan nasib masyarakatnya yang berada di kalangan bawah.

\section{Hasil Dinas Sosial dan Tenaga Kerja Kota Subulussalam dalam Mengatasi Pengemis}

Hasil wawancara yang dilakukan peneliti dengan Bapak Ridwan S. Sos. Sebagai Karyawan Dinas Sosial dan Tenaga Kerja Kota Subulussalam. Beliau mengatakan hasil yang dicapai oleh Dinas Sosial dan Tenaga Kerja Kota Subulussalam selama menjalankan programnya belum efektif karena Dinas Sosial dan Tenaga Kerja belum punya penampungan atau/tempat rehabiltas untuk pengemis. Selain itu juga "Hambatan-hambatan yang sering dihadapi dalam melakukan razia terhadap pengemis, para pengemis sudah tau terlebih dahulu, ketika mobil keamanan datang, setelah mobil pergi mereka kembali lagi melakukan aksinya sebagai seorang pengemis. Biasanya yang melakukan razia berjumlah 10-15 orang mereka turun langsung kelapangan untuk menangkap pengemis yang ada di Kota Subulussalam.

Hal ini yang dikatakan oleh Pak Anhar sebagai Satpol PP Kota Subulussalam. Beliau mengatakan bahwa hambatan dalam merazia pengemis itu seperti mereka memberontak, atau berusaha melarikan diri. Pak Anhar juga mengatakan jika sudah tertangkap mereka akan dibawa ke Dinas Sosial dan Tenaga Kerja Kota Subulussalam, lalu Dinas Sosial dan Tenaga Kerja Kota Subulussalam akan mengatasinya, seperti memberikan motivasi kepada pengemis dan meminta Kartu Tanda penduduk (KTP), selanjutnya mengembalikan mereka ke kampung halaman masing-masing.

Jika kedapatan kembali menjadi pengemis di jalanan dan di tankap oleh petugas, mereka akan dilaporkan kepada pihak yang berwajib untuk diproses sesuai dengan peraturan perundangan yang berlaku.

\section{Upaya/Solusi Pemerintah dalam Mengatasi Pengemis}

Berikut adalah beberapa upaya/solusi yang telah di lakukan pemerintah dalam mengatasi pengemis masalah penegmis sebagai berikut: 
1. Membuat peraturan perundang-undangan yang berkaitan dengan permasalahan sosial secara umum yang di dalamnya termasuk juga permasalahan pengemis seperti UU No. 11 Tahun 2009 tentang Kesejahteraan Sosial.

2. Mendirikan kementerian-kementerian, badan-badan, atau lembagalembaga yang memiliki program untuk kesejahteraan masyarakat baik berupa bantuan tunai maupun bantuan pemberdayaan.

3. Mengadakan razia di daerah rawan pengemis melalui satpol PP.

4. Mengadakan penampungan sementara.

5. Melakukan penampungan sementara.

6. Melakukan pembinaan mental dan keterampilan sesuai bakat lewat lembaga-lembaga pelayanan yang ada .

7. mengembalikan ke daerah asal atau ke panti rehabbilitasi dan resosialisasi.

8. Menyadarkan dan membina pihak-pihak yang terkait dalam jaringar. pengemis.

\section{PENUTUP}

Dari hasil penelitian yang telah dipaparkan diatas, maka dapat disimpulkan bahwa Dinas Sosial dan Tenaga Kerja Kota Subulussalam berdiri berdasarkan Qanun Kota Subulussalam Nomor 2 Tahun 2016 tentang pembentukan dan Susunan Perangkat Daerah Kota Subulussalam sebagai amanat dari Peraturan Pemerintah Nomor 18 Tahun 2016 tentang Perangkat Daerah. Selanjutnya, Dinas Sosial dan Tenaga Kerja Kota Subulussalam ini adalah salah satu Dinas dalam lingkup pemerintah Kota Subulussalam.

Strategi yang digunakan Dinas Sosial dan Tenaga Kerja Kota Subulussalam dalam mengatasi pengemis adalah dalam betuk Sosialisasi Dinas Sosial dan Tenaga Kerja Kota Subulussalam kepada masyarakat, dan Pembinaan Kesadaran Islam.

Dalam menjalankan programnya, Dinas Sosial dan Tenaga Kerja Kota Subulussalam masih banyak hambatan-hambatan/kendala yang dihadapi oleh Dinas Sosial dan Tenaga Kerja itu sendiri, yaitu: Belum tersedianya panti rehabilitas sosial atau penumpangan untuk pengemis yang tertangkap, percuma 
saja karena pengemis yang tertangkap hanya dilakukan pendataan setelah itu dibebaskan, kemudian mereka mengulangi perbuatannya karena terdesaak oleh kebutuhan sehari-hari.

Pekerjaan patroli yang dilakukan oleh Dinas Sosial dan Tenaga Kerja sering mendapatkan perlawanan, dan kegiatan penanganan pengemis ini yaitu ditemukannya wajah lama yang pernah terjaring razia, jumlah razia sekitar 10-15 orang.

Pengemis yang ada di Kota Subulussalam termasuk kategori anak-anak dan pengemis lanjut usia, sehingga pada saat melakukan pembinaan sulit memberikan penghargaan seperti pengemis lainnya.

Melihat permasalahan yang telah ditangani oleh Dinas Sosial dan Tenaga Kerja Kota Subulussalam dalam mengatasi pengemis, sejauh ini hasil yang dicapai sudah berjalan dengan baik, namun belum sepenuhnya terealisasi dengan sempurna. Dan bekerja sama dengan anggota keamanan atau Satuan Polisi Pamong Praja (SATPOL PP) dan juga masyarakat lainnya yang bisa membantu dalam pelaksanaan program yang ada di Dinas Sosial dan Tenaga Kerja Kota Subulussalam.

\section{DAFTAR PUSTAKA}

Adi Isbandi Rukminta, 2013, Kesejahteraan Sosial (Jakarta: PT rajaGrafindo Persada).

Adon Nasrullah Jamaludin Adon Nasrullah, 2015, Sosiologi Perkotaan, (Bandung: Cv Pustaka Setia).

Asrul, 2013, Kepemimpinan Pendidikan Kontemporer, (Bandung:Citapustaka).

Bungin Burhan, 2007, Metodologi Penelitian Kualitatif , (Jakarta: PT RajaGrafindo Persada).

Irfan, \& Juliandi Azuar, 2013, Metodologi Penelitian Kuantitatif, (Bandung: Citapustaka Media Perintis).

Kuswarno Engkus, 2016, Dasar-dasar Patologi Sosial, (Bandung: Cv Pustaka Setia).

Moleong J Lexy, 1993, Metodologi Penelitian Kualitatif, (Bandung: PT Remaja Rosdakarya). 
Miftachul Huda Miftachul, 2009, Pekerjaan Sosial dan Kesejahteraan Sosial, (Yogyakarta: Pustaka Pelajar).

Pemerintah Kota Subulussalam Dinas Sosial dan Tenaga Kerja, 2016, Program Dinas Sosial dan Tenaga Kerja, (Subulussalam).

Syanto Bagong, 2005, Metode Penelitian Sosial, (Jakarta: Kharisma Putra Utama).

Suprayogo Imam, 2003, Metodolgi Penelitian Sosial, (Bandung: PT Remaja Rosdakarya offset).

Syahrizal Darda Rukiyah L, 2013, Undang-undang Ketenagakerjaan dan Aplikasinya,(Jakarta: Dunia Cerdas).

Suud Muhammad, 2006, Orientasi Kesejahteraan Sosial , (Jakarta: Prestasi Pustaka Publiser). 